\title{
EXPERIMENTAL SIMULATION OF GESTATIONAL CHANGES IN THE VAGINA OF THE MOUSE
}

\author{
R. DEAN SCHICK \\ Contribution from the Department of Zoology, The Dniversity of Michigan, \\ Ann Arbor, and the Department of Physiology, The Ohio \\ State University, Columbus
}

TWELVE TEXT FIGURES AND TWO PLATES (TWELVE FIGURES)

INTRODUCTION

When Allen ('22) first described epithelial changes for the mouse and associated them with estrus and ovarian changes, he was convinced that the epithelial proliferation exhibited by the vagina was produced during the follicular phase of ovarian activity. The presence of corpora lutea in the mouse ovary at all times in various stages of development and degeneration seemed to minimize the significance of these structures as a source of growth-stimulus in the mouse.

Later, Allen, Doisy et al. ('24, '27) demonstrated that vaginal proliferation produced by injected follicular preparations was true hyperplasia, and the importance of the follicular hormone in this respect became undeniable. But the specific role of the follicular hormone in stimulating genital growth and the concomitant relationships of the anterior pituitary, thyroid, adrenal, and other growth-promoting substances still justify investigation. It is also desirable to establish distinct differences and similarities between primate and rodent, since apparent resemblances often invite unwarranted comparisons. Growth and degeneration characterize estrous and menstrual reproductive cycles alike. The phases 
of epithelial growth parallel follicular growth in both groups, followed by sloughing and repetition after an interval of quiescence (Allen et al., .39). There are, nevertheless, important distinctions that should always be kept in mind.

The estrous vaginal response in the mouse is clearly marked by proliferation, stratification, cornification and desquamation of the epithelium. If copulation occurs, this sequence is interrupted. The induced changes are the same whether the mating is fertile or not and characterize pseudopregnancy and early pregnancy alike. The superficial layers of the vaginal epithelium become cuboidal and columnar in shape, rather than squamous, undergo active secretion and become filled with mucous vacuoles. This mucosa also becomes somewhat folded. Other layers of the vagina show no distinctive changes at this time, but the vagina as a whole undergoes a slow increase in weight and circumference. Pseudopregnancy ends after 10-11 days by renewed proliferation, cornification and desquamation. True pregnancy changes in the vagina, involving further growth of the vaginal wall, begin to occur 11-12 days after fertile copulalation (Schick, '43).

Late or true pregnancy changes in the vagina involve a rapid increase in weight (238\%) terminated by delivery, a marked increase in the mucosal circumference (180\%) accompanied by a secondary folding of this layer, increased mitotic activity and hypertrophy in all layers of the vaginal wall (verified by a $158 \%$ increase in dry weight), increased vascularization and loosening of the extra-epithelial layers, and a slow, gradual increase $(50 \%)$ in the external perimeter (op. eit.). The present experiments were undertaken in an attempt to superimpose experimental treatment upon normal, non-pregnant (virgin and pseudopregnant) mice, in much the same way that true pregnancy is projected upon an otherwise intact anatomy and physiology, and thus simulate the changes brought about in the vagina by actual pregnaney. 
Experimental animals were of the same albino stock used in a study of vaginal changes during pregnancy, and were selected and cared for in the same way throughout (op. cit.). Uniform age-weight groups in the same stage of the estrous cycle were treated either while virgin, or while pseudopregnant, i.e., after mating with vasectomized males. Although the immediate changes produced by copulation are relatively small, they may be essential to the more extensive changes which occur late in pregnancy.

Materials for injection were obtained from the following sources. Theelin in peanut-oil and Antuitrin-S were supplied by Dr. Oliver Kamm of Park, Davis and Company. Progesterone and sweet almond-oil were supplied by Dr. George Cartland of Upjohn Company. Testosterone propionate was supplied by Dr. Erwin Schwenk of Schering Corporation. The author acknowledges with appreciation these generous contributions. Colchicine and glutathione were purchased from Merck and Company and Eastman Kodak Company, respectively. Whole follicular fluid was aspirated from the graafin follicles of fresh hogs' ovaries, collected at a slaughterhouse. Fresh, functional corpora lutea, also from hogs' ovaries, were chopped and injected as tissue fragments by means of a 3 inch no. 16 gauge needle and a wire plunger, or by air-pressure with a syringe. The same method was also used for the injection of fresh placental tissue, taken from mice in late stages of pregnancy.

An average dose of $68.4 \mathrm{mg}$. of luteal or placental tissue was administered at each injection. Although this dose seems high at first consideration (a greater mass than the whole diestrous vagina itself) it has been shown that the concentrations of hormone to be expected in such a quantity are not excessive (Robson and Wiesner, '31). On the other hand, the effects of the decomposing tissue cannot be considered to be conducive to optimum results even in mice, which are acclaimed 
for their high resistance to infection. Some of the placental tissue showed evidence of viability at the time of sacrifice, although it was not examined histologically. But most of it, especially the luteal tissue, was badly decomposed and infiltrated with pus a few days after injection.

Antuitrin-S and glutathione are soluble in water and saline, therefore, control-injections were performed only for the preparations which were dissolved in oil. Theelin and testosterone propionate required controls injected with peanutoil. Another group was injected with sweet almond-oil as a control for progesterone injections. Neither of these oils affected the natural estrous cycle. This is important because any natural variation in the length of the different periods would alter the average weight and circumference after an 18-day period of treatment, depending on the coincidence of estrous (maximal) and diestrous (minimal) epithelia. Starting injections when vaginal smears of all mice in a group are the same does not mean that they will still be the same after 2 or 3 weeks of treatment, even though essentially the same treatment is applied to all.

All preparations were kept in an electric refrigerator when not in use. They were warmed to body-temperature before injection. When possible, fresh follicular fluid, corpora lutea, and placental tissue were collected immediately before injection or implantation. A few times it was necessary to keep them on hand as long as 2 days. Methods of weighing, measuring, and microscopic study were the same as explained in a previous report (Schick, '43).

Since diestrus represents an intermediate stage between epithelial regeneration and degeneration, mean values of the vaginal weights and circumferences during diestrous and estrous were chosen as norms for experimental comparison when the estrous cycle was not interrupted by treatment. Diestrous (D), estrous (E), and pregnancy-means (as of days pregnant) are plotted on all graphs for comparison.

Mucification of the epithelium, hypertrophy and hyperplasia of connective and muscular tissues, and relaxation of 
tissue with infiltration of fluid must accompany the quantitative changes of the whole vagina to truly simulate pregnancy. Knowing the epithelial condition of a series of vaginas, one may proceed to draw conclusions on the basis of vaginal weights and circumferences, for it has been shown that changes in the epithelium affect weight and circumference more than changes which normally occur in the other layers (op. cit.). A vagina demonstrating only cornified epithelium should fall within the range of estrus. A vagina heavier than average for estrus, but no larger in circumference, is evidence of excessive epithelial proliferation. Vaginas larger than average, but not heavier, must have undergone tangential proliferation. Mucified vaginas can be said to resemble those of pregnancy in so far as their weights and circumferences match established means. Weights which agree with 14 days of pregnancy, but circumferences of 18 days would indicate excessive tangential proliferation. Such inference is the basis of many of the following conclusions.

PROCEDURE AND OBSERVATIONS

Estrogens. Doses of $0.001,0.002$, and $0.003 \mathrm{mg}$. of theelin in peanut-oil were injected every 4 days into three groups of virgin mice of comparable age and weight, beginning in diestrus. Another group, given $0.002 \mathrm{mg}$. theelin, received the initial injection during estrus. These groups were all sacrificed on the sixteenth day after injections were begun. Another series of animals was injected with $0.004 \mathrm{mg}$. doses of theelin every fourth day beginning in estrus and these were sacrificed on the sixteenth and eighteenth days of the experiment. A special group received thirteen doses $(0.004 \mathrm{mg}$. daily) starting in estrus and ending on the eighteenth day. A final group received $0.2 \mathrm{cc}$. of whole, fresh follicular fluid every other day, beginning in diestrus and continuing for 18 days. The results are summarized in graphs I and II.

Animals injected with theelin show an increase in vaginal weight and circumference in proportion to the amount of theelin administered and are within the diestrous-estrous 

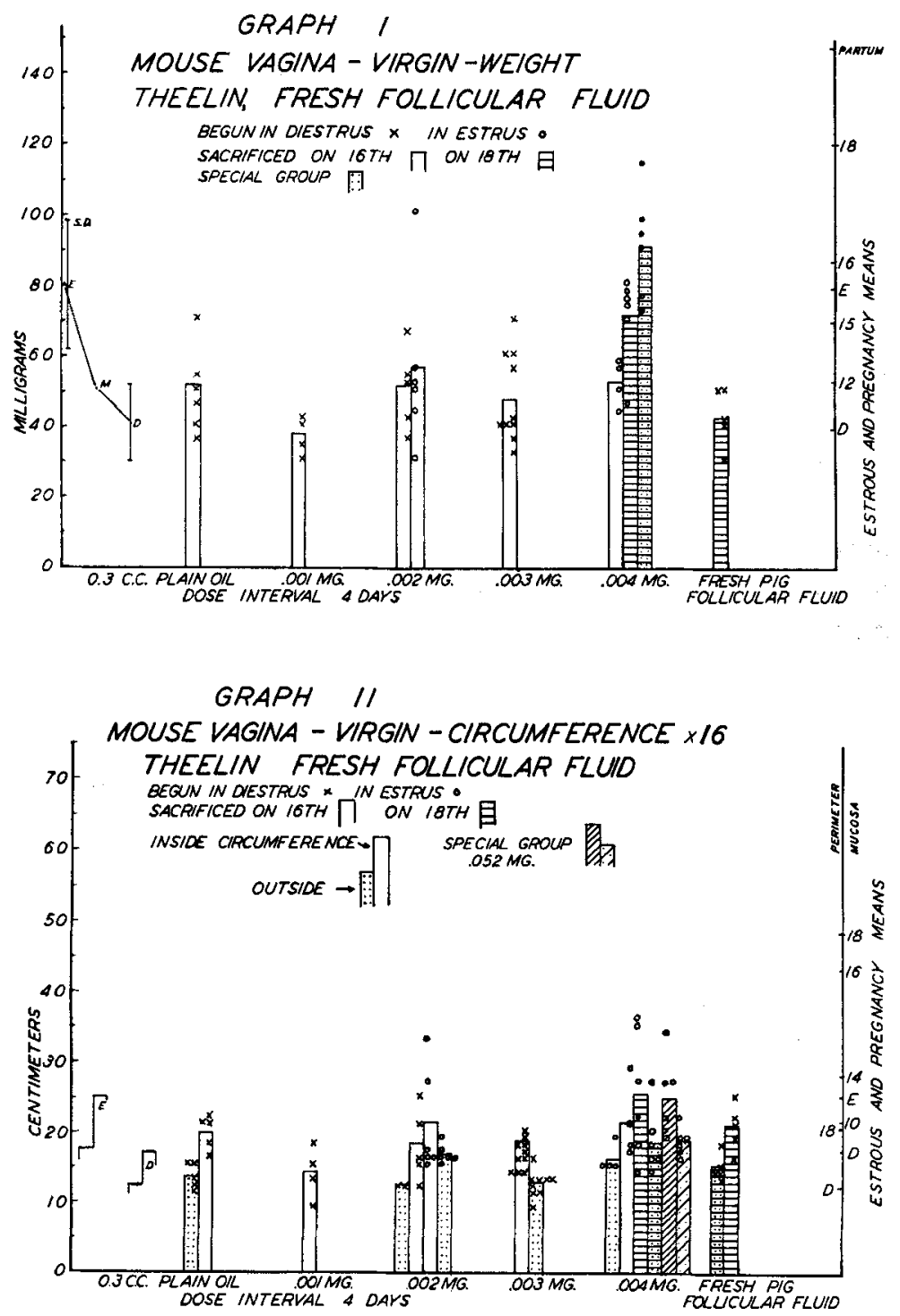
range with one exception. The group receiving the largest dose produced slightly heavier vaginas than those of estrus, though not larger in circumference. The group which received whole follicular fluid was likewise within the range of estrous weights and circumferences and resembled theelininjected animals in other respects, in spite of foreign protein contamination.

Histological study confirms the conclusion that changes in the vaginas of virgin animals treated as above are typical of natural estrous changes. None of these vaginas has a mucified epithelium; none shows unusual hyperplasia or hypertrophy of extra-epithelial tissue. Only the vaginas of animals injected with whole follicular fluid show any relaxation of the connective tissue or muscle, and it is not marked in these.

Several groups of pseudopregnant (nulliparous) mice were injected with $0.002 \mathrm{mg}$. of theelin every 4 days. One series was begun at estrus, another 4 days post-estrus. Groups of these were sacrificed every 4 days. Their values are plotted in graphs. III and IV. Maximal means in vaginal weight and circumference were reached on the tenth and twelfth days of treatment. Means of the post-estrous injected groups are generally higher than those injected first in estrus. It is of interest that a larger proportion of the post-estrous injected animals killed on the eighth and tenth days of treatment, have secretory vaginal epithelia. One individual in each of the 16- and 18-day groups has a mucified vaginal epithelium. Of the series injected first in estrus only three individuals have secretory vaginal epithelia beyond the period of pseudopregnancy.

Only certain individuals of these groups justify comparison with pseudopregnancy or early pregnancy, namely those having secretory vaginal epithelia. Likewise, only data from animals which retained secretory vaginal epithelia beyond the normal range of pseudopregnancy should be compared with means of late pregnancy. A few individuals, some of which have larger and heavier vaginas than would be predicted 

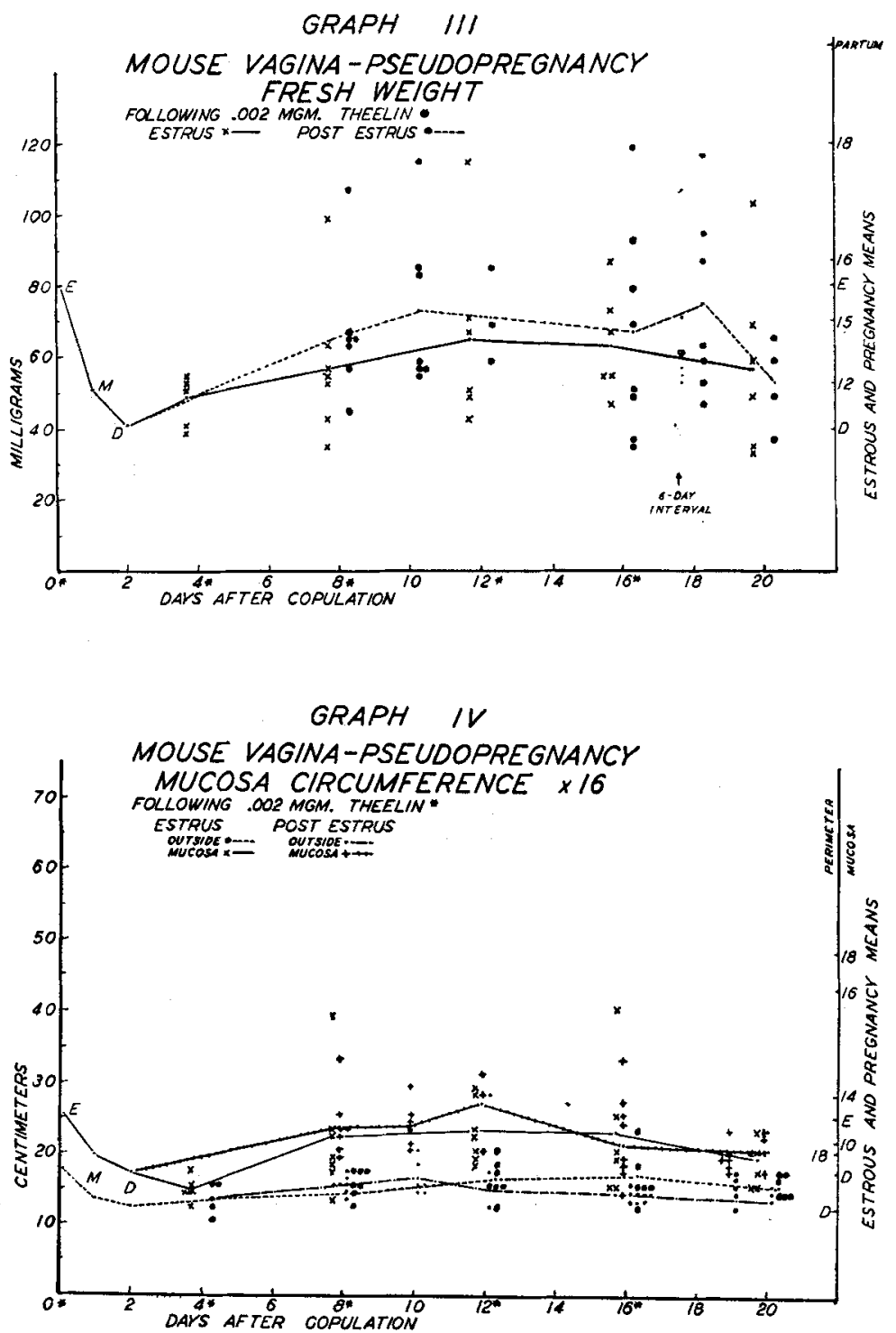
from means of pseudopregnancy or early pregnancy, fit these requirements. These fit mid-pregnancy averages with the exception of small perimeters in all but one individual. Other histological changes resembling middle or late pregnancy are wanting. It would be extremly difficult, however, to be certain that intermediate stages of cellular hypertrophy or relaxation of tissue had not occurred in any case.

Progesterone and estrogen antagonism. Twenty virgin mice were treated in this series. Six received $0.3 \mathrm{cc}$. of plain almondoil every 4 days as controls. Five animals were injected with $0.3 \mathrm{mg}$. of progesterone in $0.3 \mathrm{cc}$. of almond-oil every 4 days, and five others received $0.6 \mathrm{mg}$. of progesterone in $0.12 \mathrm{cc}$. ( 2 minims) of almond-oil every 4 days. The four remaining animals received implants of fresh corpus luteum every other day. All groups were sacrificed on the sixteenth day following the first injection.

The control-group has no individuals with secretory epithelia, but ranges from diestrus to estrus in development. Experimental animals which received the smallest dose of progesterone have $100 \%$ diestrous vaginal epithelia, while the group which received twice that amount of progesterone has $60 \%$ secretory and $40 \%$ proliferative vaginal epithelia (figs. 1 and 7). Vaginal weights and circumferences of these animals are within the range of normal estrus (graphs V and VI). Vaginas from the group which received the small dose are heavier, but have smaller circumferences (both inner and outer) than those of the group which received the large dose, although sections from one or two vaginas in each of these groups could not be measured accurately. The mice which were injected with fresh corpus luteum have vaginas with much smaller. circumferences but are about as heavy as those of the group which received the largest dose of progesterone. All of these are secretory (figs. 2 and 8 ).

Connective tissue and muscular layers are mostly compact in vaginas of animals injected with progesterone and corpus luteum. The tissues are noticeably looser in the mucified vaginas (figs. 7 and 8 ). Accelerated proliferation is not 

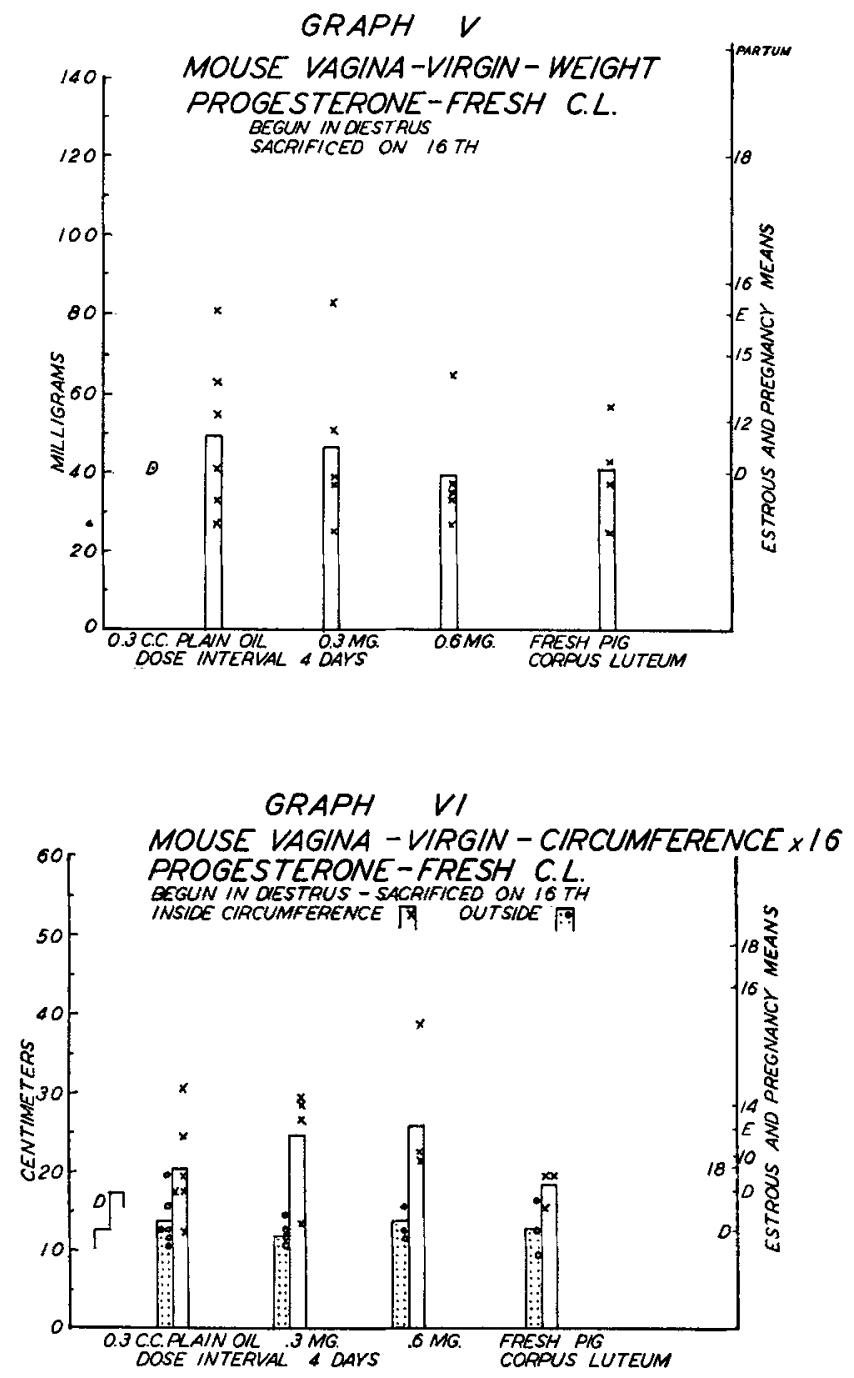
noticeable even in the epithelium of these organs, although it is indicated by their circumferences. Ovaries of all animals injected with progesterone and corpus luteum have more functional corpora lutea than ovaries of controls.

Four groups of animals were injected with combinations of progesterone and theelin. All received three doses of progesterone, $0.3 \mathrm{mg}$. each, 4 days apart. Progesterone was supplemented in respective groups by one, two, three, and four doses $(0.002 \mathrm{mg}$.) of theelin. The two groups which received one and two doses of theelin were sacrificed on the sixteenth day of the experiment. Those receiving three and four doses of theelin were sacrificed 20 days after beginning treatment.

Vaginal epithelia of all these animals are cornified. The fresh vaginal weights are within the range of normal estrus (graph VII). Except for two individuals there is little variation in a consistent correlation between vaginal weights and the amount of estrogen received. Circumferences show the same agreement, except for the 20-day group which received the most theelin (graph VIII). The extra-epithelial tissues of mice injected with progesterone and theelin show little metaplasia. It is concluded that the amount of progesterone administered was insufficient to inhibit epithelial hyperplasia and cornification.

Fresh placental tissue. Six groups of virgin and two of pseudopregnant mice were treated with fresh placental tissue from mice in late pregnancy. The first series of experiments with virgins included four groups, three of which were given subcutaneous placental implants every 4 days beginning in estrus, and were killed on the fourteenth, sixteenth, and eighteenth days after initiation of treatment. The fourth group of virgins received diced placental tissue directly in the vagina every other day, and were sacrificed on the eighteenth day. Graphs IX and X summarize the quantitative data for these animals.

Sixty per cent of the first two groups have secretory vaginal epithelia, while only one of the 18-day animals has a mucified vagina. All mice which received placenta in the 

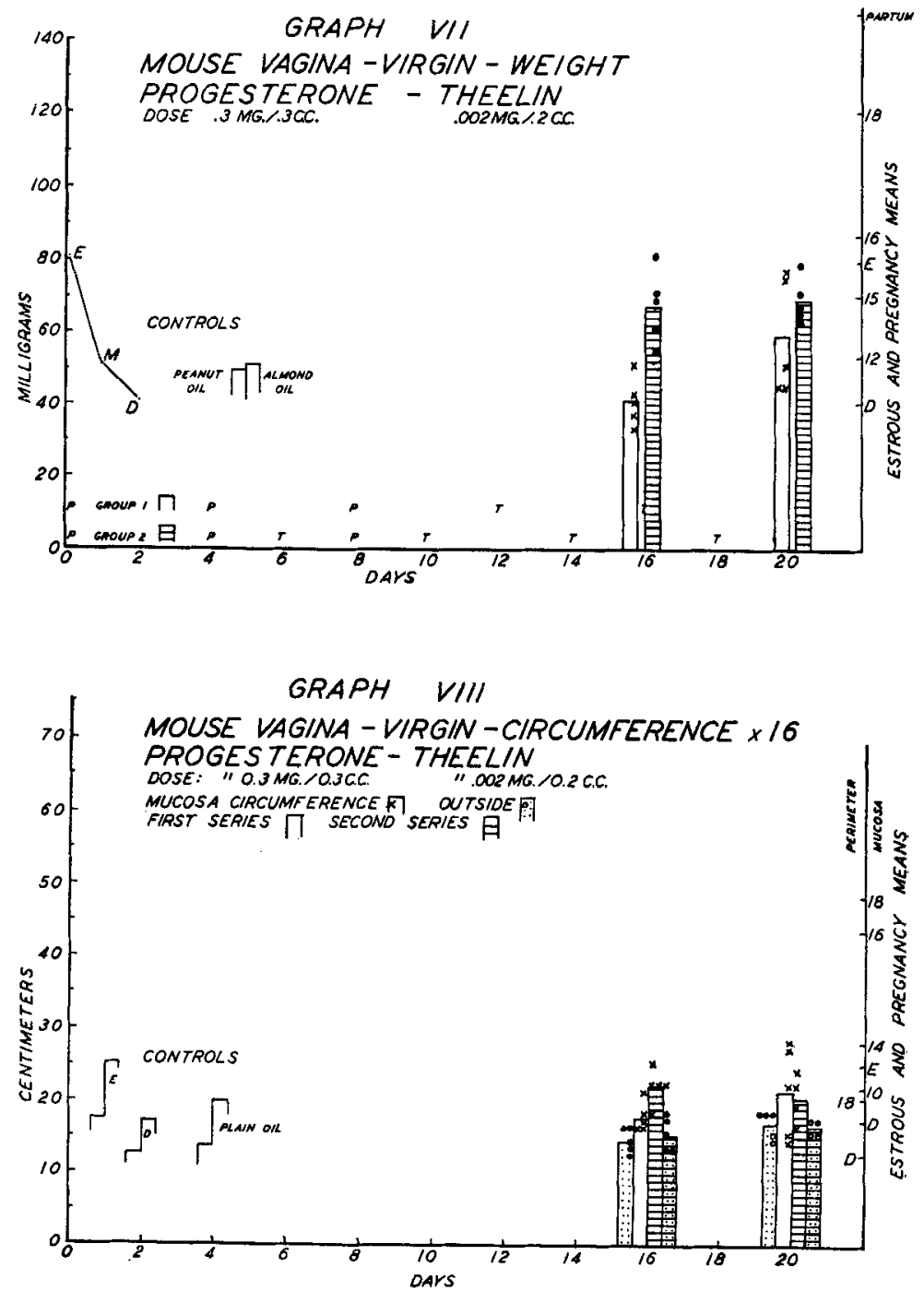

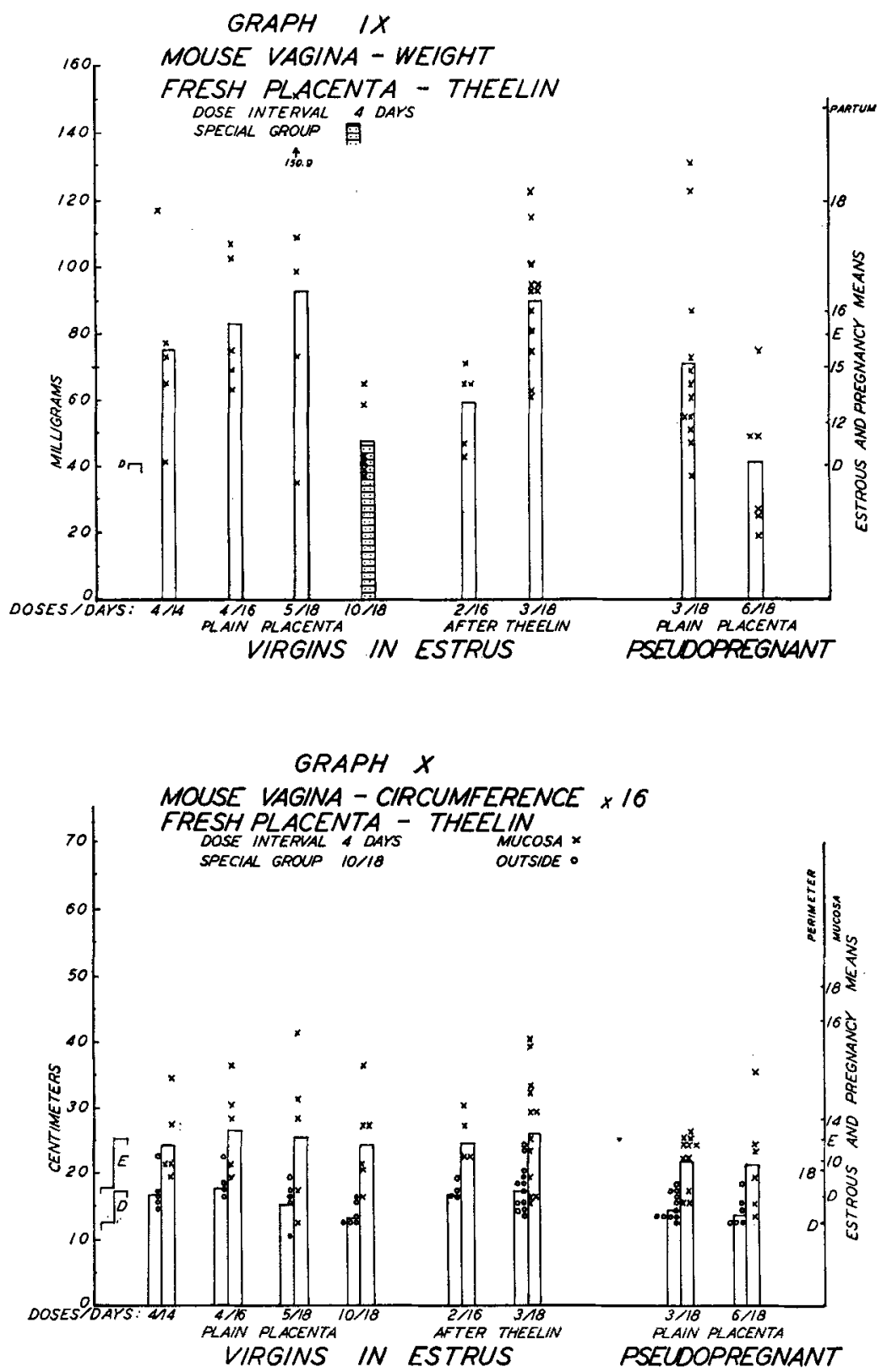
vaginal lumen had secretory epithelial development (figs 4 and 10), and several layers of actively dividing cells beneath the deep folded mucosa. Although the lamina propria is rather compact the muscularis is loose, particularly the longitudinal fibers. The adventitia is thin. Ovaries of the same animals show only a few large corpora lutea and numerous small, growing follicles.

The second series of virgin mice were given injections of theelin prior to placenta, $0.004 \mathrm{mg}$. doses every fourth day beginning in estrus. One group was given two injections of fresh placental tissue, the other three injections. These animals were sacrificed on the sixteenth and eighteenth days of treatment respectively (graphs IX and X). Only a few individuals of either group show even early gestational mucification of the vaginal epithelium, and none of the other characteristic changes of pregnancy could be detected. Ovaries of these animals have numerous small follicles.

Two groups of pseudopregnant mice were given placental treatment. One received injections every 4 days; the other received injections every other day. Both groups were sacrificed on the eighteenth day of the experiment. Their data is presented on graphs IX and X also. One individual of the group which received the smaller number of placental injections has the typical vaginal epithelium of pregnancy. All individuals of the other pseudopregnant group had some vaginal mucification with little folding of the mucosa.

Vaginal weights of all placental treated mice were quite variable and standard errors for their means were high. The circumferential means were less variable, all groups being very nearly the same. Although the means for vaginal circumference and weight fall within the range of normal diestrous-estrous variation, certain individuals of these groups qualify for classification as of pregnancy because of histological metaplasia. It is also interesting to note that most of these same individuals, though not all, had large, functional corpora lutea, stimulated mammae, and ligamentous pubic symphyses. 
Antuitrin-S. Two groups of virgin and one of pseudopregnant mice were compared in this experiment. One virgin group received 0.2 ec.-injections of Antuitrin-S every other day beginning in estrus. The other virgin group received five 0.004 $\mathrm{mg}$. injections of theelin starting in estrus, in addition to 0.2 cc. of Antuitrin-S every fourth day (staggered with theelin). The pseudopregnant animals received $0.2 \mathrm{cc}$. of Antuitrin-S on the sixth, tenth, and fourteenth days following copulation. All groups were sacrificed on the eighteenth day of the experiment (graphs XI and XII).

During the time of treatment the vaginal epithelium of at least two of the virgin animals passed through a secretory phase. Only one of the animals treated with theelin responded by secretory metaplasia, and this one only slightly. Other individuals in these groups have cornified vaginal epithelium. The pseudopregnant animals responded much better. Only one has cornified vaginal epithelium, and three have well developed vaginas as of late (15-16 days) pregnancy (figs. 3 and 9). One vagina is in a pro-secretory stage of metaplasia. Extraepithelial layers are loose and vascular (fig. 9).

Glutathione. On the assumption that a solution of glutathione several times the concentration ordinarily found in blood might accentuate its effect on growth processes, a $0.2 \%$ solution was employed. A dose of $0.2 \mathrm{cc}$. of this solution $(0.4$ mg. glutathione) was injected into four groups of virgin and two of pseudopregnant mice. Two of the virgin groups received five and nine injections respectively. Two others each received four injections of glutathione, supplemented by three doses of theelin, in doses twice as large for one group. The pseudopregnant groups received three and six injections of glutathione respectively. All groups were sacrificed on the eighteenth day of the experiment.

Results are extremely variable, compared to those of most of the preceding groups. One or two individuals of each group treated with glutathione have secretory vaginas. The virgin groups, excepting the one given the most theelin, developed some secretory vaginas resembling those of mid- 

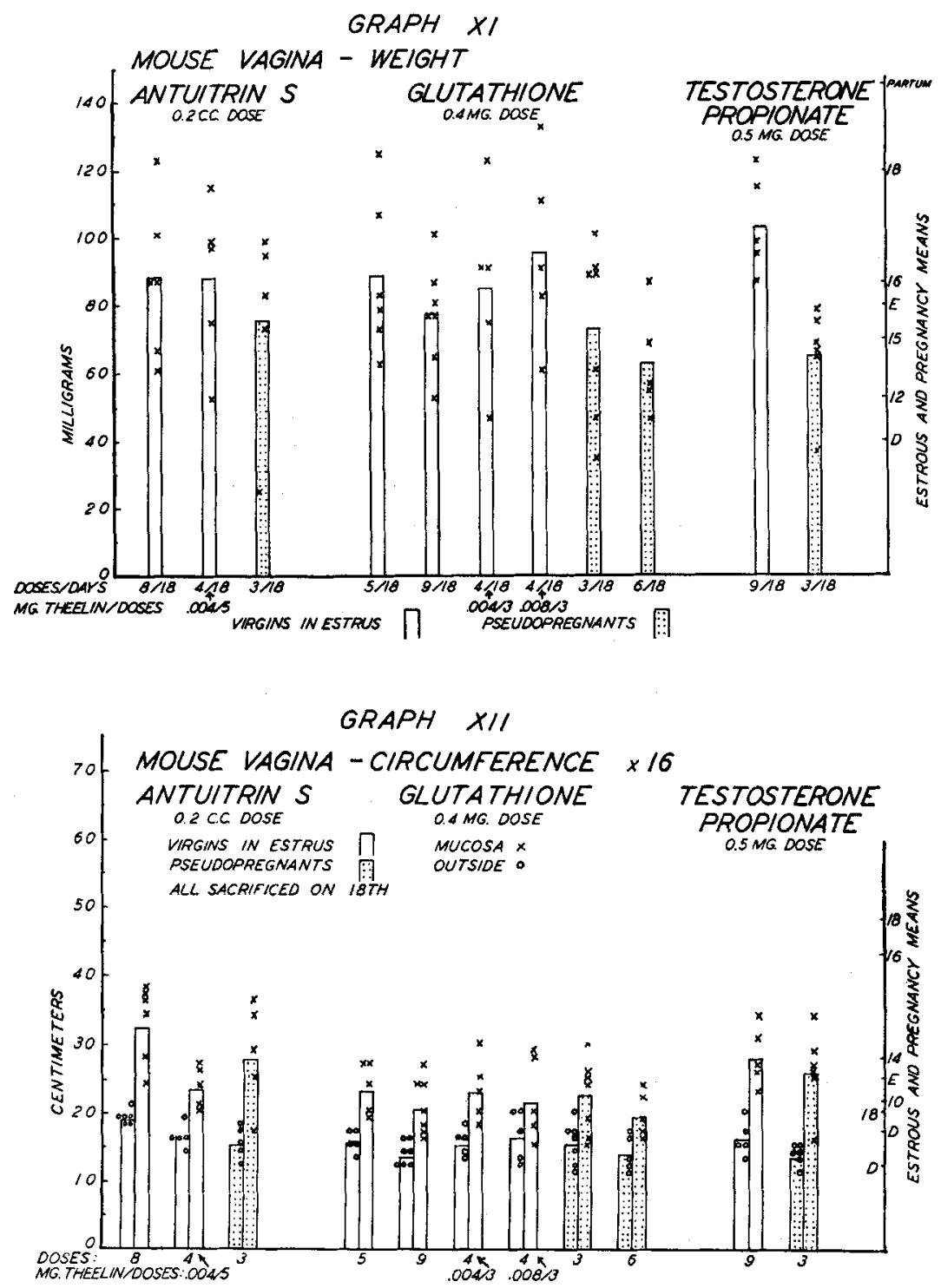
pregnancy (figs. 5 and 11). Vaginas of the pseudopregnant groups were quite variable, but these animals also received less glutathione than the virgins. The fact that some of the cornified vaginas are even heavier than any secured in normal estrus indicates that glutathione influenced a proliferative stimulus (graph XI). This effect was greater when glutathione was supplemented by theelin. Ranges in vaginal circumference are within the estrous-diestrous extremes in all groups, and individuals are less variable in this respect (graph XII).

Vaginal smears indicated that the estrous cycles of mice treated with glutathione were lengthened. Gains in general body-weight were not excessive during the experimental period, but were not followed longer. Histologically the tissues appear normal except for a somewhat more compact lamina propria, due to the presence of many collagenous fibers. Mice having secretory vaginas also have at least a few functional corpora lutea, so the vaginal effect may have been indirect.

Testosterone propionate. Only two experimental groups were compared. Five virgins received injections of testosterone propionate $(0.5 \mathrm{mg}$.) every other day beginning in estrus. Six pseudopregnant mice were given the same dose on the sixth, tenth and fourteenth days after copulation. All went into continuous diestrus soon after injections began. Both groups were killed and examined on the eighteenth day of the experiment. See graphs I and II for oil-injected controls.

All of the experimental animals have well-developed, secretory vaginas (figs. 6 and 12), although a few already show some signs of degeneration (leucocytic infiltration). Vaginas of animals which received the most testosterone propionate are heavier - comparable to the seventeenth day of pregnancy (graph XI). All vaginas from the group are within the range of variation in weight for that stage. The means of circumference for the virgin group match the 14-day stage of pregnancy (graph XII). Pseudopregnant animals, with a single 
exception, consistently resemble vaginal development of middle pregnancy or beyond.

Histologically, vaginas of both groups are indistinguishable, except that the mucosa is somewhat thinner in pseudopregnant animals in spite of numerous mitotic figures. The lamina propria and muscularis are well developed, loose, and vascular (fig. 12). That this general effect was not mainly provoked through the activity of corpora lutea is verified by the predominance of follicles in the ovaries of the treated animals. Even the ovaries of pseudopregnant mice show only occasionally functional corpora lutea.

\section{DISCUSSION}

Normal animals of the same age and weight were selected and subjected to the same treatment except for the experimental variable. When such uniform groups fail to produce uniform results, the cause can be attributed only to uncontrolled, internal variations. Normal differences in the length of estrous phases occur (Allen, '22), and it is true that occasional individuals, otherwise apparently normal, are sexually abnormal or even sterile. It is not unlikely that some of the aberrant individuals in the present experiments were of this kind.

Many of the experimental groups include individuals with a high deviation from the rest of the group, having exceptionally large or exceptionally small vaginas. Differences with respect to mucification and cornification of the vaginal epithelium are also significant as has been repeatedly demonstrated above. As is customary, all individuals of an experimental group were considered collectively for a statistical mean and a standard error. In many cases, differences with respect to vaginal histology justify secondary grouping or even individual consideration with respect to the stage of pregnancy simulated.

It has been demonstrated that most of the increase in vaginal weight during pregnancy is due to the addition of new protoplasm, indicated by an increased dry weight (Schick, '43). 
To obtain such data for injected mice would require again as many animals as were examined (over 300) and was considered impracticable under the circumstances. The conclusions reached in this report with respect to pregnancy-simulation would be greatly strengthened by confirmatory data regarding dry vaginal weights.

Estrogens. Estrogens have been accredited with stimulating many of the changes observed in the vagina of the mouse during pregnancy. Epithelial proliferation is produced by folliculin (and other estrogens) in any amount (Allen et al., '24, '37; Loeb and Kountz, '28; and many others). Epithelial mucification is produced by estrin in small doses (Meyer and Allen, '33), or when inhibited by progesterone or testosterone (Robson, '38). Tissue infiltration, hyperemia, and general osmotic changes are produced by inhibiting estrogenic effects with atropine, and imitated by yohimbine-injections (Hechter, Lev and Soskins, '40). A differential epithelial response to estrogens, decreasing toward the cervix, has been repeatedly observed (Suntzeff et al., '38; Lipschutz et al., '40; Robson and Adler, '40).

The muscular and connective tissue layers of the vagina have been subjected to fewer experimental studies. Following the injection of estrogen, Loeb, Suntzeff and Burns ('39) reported an increase in the amount of fibrous hyalin (collagenous) connective tissue in the mouse vagina, accompanied by marked relaxation and much fluid. Worthington and Allen ('39) reported slight stimulation of vaginal connective tissue (mitosis) following estrone and injections of colchicine in monkeys; none was observed in muscular cells.

Epithelial hyperplasia and cornification resulted from injections of virgin and pseudopregnant mice. Effects were less marked when theelin was injected after sterile copulation, but certain individuals were induced to retain epithelial mucification well beyond the normal range of pseudopregnancy. At least one of these individuals had a vaginal development comparable to 14-15 days of true pregnancy. This development was probably brought about indirectly through the pituitary 
after the manner demonstrated by Nelson ('35) and others (Donahue, '38; Merckel and Nelson, '40).

Groups injected first in diestrus consistently produced larger vaginas (graphs III and IV). Groups injected in estrus show less individual variation than groups injected in diestrus or 4 days after sterile copulation. This is probably due to the fact that an exact stage of estrus can be more accurately selected than an exact stage of diestrus.

Progesterone and estrogen antagonism. The probability that corpora lutea exert some influence on vaginal changes during pregnancy is indicated both by the increasing prominence of these structures in the ovary as vaginal transformations progress and by the accumulating literature clarifying the role of progestin. Its importance in the independent initiation of growth and mucification in the vagina (Corner and Allen, '29, etc.) have been somewhat discredited by further studies with standardized extracts and synthetic progestion (Allen and Meyer, '35; Hisaw, Greep and Fevold, '37 ; Korenchevsky and Hall, '37).

Progesterone brought about a marked reaction in the vaginas of injected mice in the present experiments, as did fresh luteal tissue. The smallest amount of progesterone injected prolonged diestrus without any noticeable mucification or metaplasia, but exerted some interference with normal proliferation (some tangential). A double amount produced $60 \%$ mucification and a more noticeable looseness in all tissues of these vaginas, in addition to some tangential proliferation, as indicated by comparison of weight and circumference-means. There was not sufficient estrogen in the hog-luteal tissue or from follicles of treated animals to depress the progestineffect of mucification exerted by this tissue. Radial proliferation was likewise inhibited by luteal tissue.

The antagonistic effects of progestin on estrogens and on estrous phenomena is well known (Loeb, '23; Papanicolaou, '26; Hisaw, Meyer and Weichert, '28; Loeb and Kountz, '28; Allen and Meyer, '33, '35; Moore et al., '37). Their results have been confirmed with synthetic progestin (Selye, Browne 
and Collip, '36; Lahr and Riddle, '36; Phillips, '37; Phillips and Young, '38; Robson, '38; and others). Vaginal mucification can be produced in normal mice, rats, and guinea pigs by the injection of progesterone, or in spayed animals by injecting combinations of estrogen and progesterone (Hisaw, Meyer and Weichert, '28; Meyer and Allen, '33; Desclin, '34; Korenchevsky and Hall, '37; Klein, '38).

Injections of theelin following moderate doses of progesterone completely dominated epithelial mucification in my experiments. The proliferation which occurred was in proportion to the amount of theelin administered to each group. When the results are compared to those of plain theelin, it is obvious that the same total dose produces a more pronounced vaginal weight-increase (circumference is increased only slightly) when theelin was given after progesterone (graphs I and VII). The conclusion that increased growth-stimulation was secured by certain combinations of theelin and progesterone would also help explain the variability of theelin-injected animals after sterile copulation, and why those injected with theelin after corpora lutea were well developed had larger and heavier vaginas.

Placenta. There is already good evidence that the placenta of the mouse has an important function in the physiology of pregnancy. Although mice are apparently among those animals with a relatively small amount of placental progestin, unable to survive pregnancy without the benefit of ovarian progestin (Harris, '27; Parkes, '28), it has been indicated that placental development is correlated with uterine development during pregnancy in the mouse (Selye, Collip and Thomson, '35) as well as with vaginal changes (Schick, '43). The placenta also controls excess water in tissues during pregnancy (Newton, '35; Brooksby and Newton, '38) and has a trophic effect on the ovaries and mammary glands independent of the pituitary (Newton and Beck, '39).

Evidence of a considerable amount of mucifying agent in the placenta of the mouse was secured in the present experiments. All groups treated, when not inhibited by excess 
theelin, include at least one individual with a vagina simulating development of late pregnancy. Vaginas with a large amount of hypertrophy and epithelial hyperplasia were numerous and can be accounted for on the basis of a lower ovarian supplement of progestin and a higher complement of natural estrogen, than those which show vaginal mucification. Chance coincidence could explain the few mucified cases in which the introduced placentas added just enough extra progestin to favor mucification. Pseudopregnant groups, however, all of which should have had well developed corpora lutea when injected, produced only the same small percentage of latepregnancy vaginas. Many of these show evidence of considerable proliferation, strengthening evidence of a cooperative progestin-estrogen effect. One group was $100 \%$ secretory, but had not advanced beyond the development of pseudopregnancy, even after 18 days of placental injection.

Estrogens have been assayed by direct vaginal application and a purely local effect has been demonstrated (Robson and Adler, '40). Direct vaginal stimulation with fresh placental tissue was successful in producing stages of vaginal development up to a 15-day pregnancy-type. Mechanical stimulation of the cervix was carefully guarded and the results of the group as a whole were fairly consistent. Suppression of radial epithelial proliferation and cornification, accompanied by mucification and supplemented by some loosening of the deeper tissues, are submitted as evidence of a placental progestinlike influence.

Pituitary and A.P.L. hormones. Long and Evans ('22) first reported that development of corpora lutea could be produced and maintained in the ovaries of rats by injecting extracts of the anterior pituitary. This relationship has been well established, both directly and indirectly. Mechanical stimulation of the vagina, as in swabbing, often results in epithelial proliferation and cornification (Wade and Doisy, '35; Rogers and Allen, '37; Emery and Schwabe, '36, '38). Increased estrogen-secretion or an increased sensitivity to it may be responsible for this reaction. Deeper mechanical 
stimulation, affecting the cervix, results in vaginal mucification (Long and Evans, '22; Shelesnyak, '31; Greep and Hisaw, '38). In this case the stimulation appears to involve pituitaryexcitation of corpora lutea, which in turn affects mucification by inhibiting estrogen. Another indication of intermediation by the pituitary is found in the differential response of intact animals to the injection of large amounts of estrogen (Nelson, '35; Donahue, '38; Merckel and Nelson, '40). It was found that the newly formed corpora lutea were functionally maintained when injections were begun in estrus, apparently through stimulation of the luteinizing hormone of the pituitary.

In the present experiments, injections of Antuitrin-S were successful in producing the most consistent results in pseudopregnant animals. Three individuals out of five had vaginas of an advanced type, while one remained as in pseudopregnancy and another became cornified. A large amount of epithelial proliferation occurred in treated virgins, even with stratification beneath mucification in some individuals. Apparently, Antuitrin-S has nearly as great a mitogenic effect upon the vagina as the larger doses of plain theelin used, and still produced some secretory vaginas (ef. graphs $I$ and $\mathrm{XI}$ ). The mucifying and relaxing effects are inhibited by theelin here as elsewhere. This is reflected by a much smaller mucosal circumference after theelin, for vaginas of approximately the same fresh vaginal weight. The fact that the ovaries of the animals with mucified vaginas had better developed corpora lutea, and those with cornified vaginas had more large follicles is suggestive of luteal importance in stimulation with Antuitrin-S, while the inhibition of vaginal mucification and relaxation by theelin is indicative of estrogenprogestin antagonism.

Glutathione. The effect of glutathione on vaginal growth was of interest because of the unexpected concentrations of this sulfhydryl compound in the blood of newborn and pregnant mammals (Miyachi, '37; Cadden, '38; Santavy, '38). These compounds have also been said to accelerate the healing 
of ulcers in man (Reimann and Hammett, '29) and the growth of hair follicles in mice (Hammett, '31).

Mice injected with glutathione in these experiments produced results similar to those of Antuitrin-S. The preparation used definitely showed mitogenic properties, equivalent to estrous values, and in excess of all but the largest theelindosage used (cf. graphs I and XI). When combined with theelin, the mitogenic effect of glutathione is more pronounced, but it is minimized when given in pseudopregnancy although still representing an increment well above maxima of ordinary pseudopregnancy. Since the majority of animals in these groups had cornified epithelia and since the mean circum. ferences were intermediate between estrous and diestrous values, it may be inferred that most of the proliferation in the epithelia of these vaginas is radial. Glutathione supports more successfully than it stimulates mucification, as after pseudopregnancy, but there is little progress in development beyond.

Testosterone propionate. The comparative effectiveness of several androgens in conditioning vaginal mucification was demonstrated in rats by Korenchevsky and Dennison ('36). It was also shown that some of these preparations, notably testosterone propionate, induced considerable hypertrophy of the vagina as a whole (Korenchevsky and Hall, '37), while others apparently caused vaginal opening in immature animals, followed by cornification (Deanesly and Parkes, '37). Some of these effects are debatable (Nelson and Merckel, '37), but comparative tests have shown that testosterone is definitely more effective than progesterone in inhibiting the estrogenic effect of estradiol (Robson, '38).

Testosterone propionate was consistently good in stimulating vaginal development in the mouse. All animals injected soon had secretory vaginal epithelia and maintained them thoroughout the course of treatment. Mucosal circumferences failed to increase in proportion to the vaginal weight of the virgin group, which is an indication that increased mitotic activity in the epithelium was predominantly vertical to the 
basalis. Pseudopregnant animals show a better balance between vaginal weight and circumference after treatment with testosterone propionate. Both of these resemble pregnancymeans of 14-15 days in spite of the fact that the amount of testosterone propionate injected was only one-third of that received by the virgins. In addition to less radial proliferation, mucosa and submucosa are thin and mitotic figures are numerous.

Due to similarity of treatment in many of the experiments above, one is tempted to draw conclusions regarding the relative effectiveness of methods in stimulating vaginal hypertrophy. This tendency is particularly strong in the case of testosterone propionate, glutathione, and Antuitrin-S, which were given simultaneously to the respective groups and their numbers of doses were frequently the same. The fact that nine doses of testosterone propionate produced heavier vaginas in virgins than nine doses of glutathione or eight doses of Antuitrin-S, or that three doses of Antuitrin-S produced larger circumferences than three doses of either of the others means nothing without further quantitative and qualitative comparison of the preparations. Since no attempt was made to establish equivalent dosages, comparisons of this sort are scarcely valid.

\section{SUMMARY}

1. Theelin and whole follicular fluid (hog) produce epithelial proliferation which is predominantly radial in the vaginas of virgin mice. A predisposing pseudopregnancy was no more favorable in promoting late-pregnancy changes in the vagina, although a few underwent hypertrophy beyond ordinary pseudopregnancy. Injections during diestrus were the most effective in this respect.

2. Progesterone and fresh luteal tissue (hog) were predominantly mucifying in action on the vagina of the mouse, simulating early or middle-pregnancy changes only. Some tangential proliferation is indicated by circumferential data. 
3. Evidence of cooperative activity between theelin and progesterone in effecting epithelial hyperplasia was observed.

4. Considerable vaginal stimulation was secured by treatments with fresh placental tissue (mouse) from late pregnancy. The suppression of radial proliferation and cornification accompanied by mucification of the vaginal epithelium in several animals, and general simulation of normal vaginas of late pregnancy, are submitted as evidence of a placental effect on vaginal growth during pregnancy resembling that of progesterone and testosterone propionate.

5. Antuitrin-S stimulates tangential growth and mucification in the vagina indirectly through corpora lutea as indicated by a higher percentage of late pregnancy simulations after pseudopregnancy and in the absence of additional theelin. Excessive radial proliferation of vaginal epithelium occurs when Antuitrin-S is injected in the absence of functional corpora lutea (virgins in estrus).

6. Glutathione has an accelerating effect on radial proliferation, not antagonistic to theelin, and is occasionally accompanied by mucification. The vaginal mucification of pseudopregnancy is prolonged by glutathione and general vaginal growth is somewhat improved beyond that of pseudopregnancy.

7. Testosterone propionate simulated all of the late-pregnancy changes observed in the vagina of the mouse. Large doses produced considerable radial proliferation in the epithelium. Treatment after sterile copulation produced more uniform hypertrophy of the vagina resembling that of late pregnancy.

The author makes grateful acknowledgment to Doctor Alvalyn E. Woodward, of the University of Michigan, for guidance during the progress of this work. Photographs were furnished by the Department of Physiology of The Ohio State University. Experimental and statistical data are on file at the General Library of the University of Michigan. 


\section{LITERATURE CITED}

Altin, E. 1922 The oestrous cycle in the mouse. Am. J. Anat., vol. 30, pp. $297-348$.

Alifin, E., E. A. Doisy ET AL. 1924 The hormone of the ovarian follicle; its localization and action in test animals, and additional points bearing upon the internal secretions of the ovary. Am. J. Anat, vol. 34, pp. 1.33-181.

Allen, E., AND F. A. DoIsy 1927 Ovarian and placental hormones. Physiol. Rev., vol. 7, pp. 600-650.

Allen, E., C. H. Danforth ANd E. A. Doisy (editors) 1939 Sex and internal secretions. Baltimore. Williams \& Wilkins.

Alien, E., G. M. SMith AND W. U. GARDNER 1.937 Accentuation of growth effect on genital tissues of ovariectomized mouse by arrest of mitosis with colchicine. Am. J. Anat., vol. 61, pp. 321-341.

AlLeN, W. M., AND R. K. Meyer 1933 The quantitative separation of progestin from oestrin in extracts of the corpus luteum. Am. J. Physiol, vol. 106, pp. 55-63.

1935 Physiology of the corpus luteum: the inhibition of estrin by progestin-containing extracts of corpus luteum. Anat. Rec., vol. 61, pp. 427-439.

Brooksby, J. B, AND W. H. NEWTon 1938 The effect of the placenta on the body weight of the mouse. J. Physiol., vol. 92, pp. 136-150.

Cadden, J. F. 1938 The glutathione content of the blood during the puerperium. J. Lab. and Clin. Med., vol. 23, pp. 1266-1272.

Corner, G. W., AND W. M. Alifen 1929 Physiology of the corpus liteum: production of a special uterine reaction (progestational proliferation) by extracts of corpus luteum. Am. J. Physiol., vol. 88, pp. 326-339.

Denangsy, R., AND A. S. Parkes 1937 Multiple activities of androgenie compounds. Quart. J. Fixper. Physiol., vol. 26, pp. 393-402.

Deschin, L. 1934 A propos du determinisme de la mucification vaginale chez le cobaye. Compt. rend. Soc. de biol., vol. 115, pp. 439-441.

Donahue, J. K. 1938 Effects of estrogenic hormones on sex eycle of normal rats. Eudocrinology, vol. 23, pp. 521-523.

EMERY, F. E., AND E. L. SCHWABe 1936 The vaginal smears of rats as influenced by frequent examinations. Anat. Rec., vol. 64, pp. 147-154. 1938 Increased sensitivity of the vagina to theelin, in the chronic castrated rat, as induced by the cotton swab procedure. Anat. Rec., vol. 72 , pp. 303-311.

Greep, R. A., ANd F. L. HisAw 1938 Pseudopregnancies from electrical stimulation of the cervix in the diestrum. Proc. Soc. Exper. Biol. and Med., vol. 39 , pp. $359-360$.

HAmmetT, F. S. 1931 The proliferative reaction of the skin to sulfhydryl and its biological significance. Protoplasma., vol. 13 , pp. 331-347.

HARRIS, R. G. 1927 Effect of bilateral ovariectomy upon the duration of pregnancy in mice. Anat. Rec., vol. 37, pp. 83-92.

Hechter, O., M. LEv AND S. Soskin 1940 The relation of hyperemia to the action of estrin. Endocrinology, vol. 26, pp. 73-79. 
HISAW, F. I., R. K. MEYer AND C. K. WeTCHeRT 1928 Inhibition of ovulation and associated histological changes. Proc. Soc. Exper. Piol. and Med., vol. 25 , pp. $754-756$.

HISAW, F. L., R. O. GReep AND H. I. Frevold 1937 The effects of oestrinprogestin combinations on the endometrium, vagina, and sexual skin of monkeys. $\Lambda \mathrm{m}$. J. Anat., vol. 61, pp. 483-503.

KLEIN, M. 1938 Sur l'action simultance de l'oestrone et de la progesterone dans la production et dans le maintien de la mucification vaginale ehez les rongeurs. Compt. rend. Soe. de biol., vol. 127, pp. 918-920.

Korendmevsky, V., AND M. Dexnison 1936 The histologieal ehanges in the sex organs of spayed rats induced by testostcrone and oestrone. $J$. Path. and Bact., vol. 43 , pp. 345-356.

Konenchevsisy, V., And K. HaL, 1937 The bisexual and cooperative properties of the sex hormones as shown by the histological investigation of the sex organs of female rats treated with these hormones. J. Path. and Bact., vol. 45 , pp. 681-708.

LAHR, E. L., AND O. RIDDLE 1936 Temporary suppression of oestrous cycles in the rat by prolactin. Proc. Soc. Exper. Biol. and Med., vol. 34, pp. $880-883$.

Lipschutz, A., L. Vargas, A. Jenlicky and P. Peitlolio 1940 The minimum quantity of estrogen required to induce epithelial growth of the uterine mucosa in the guinea pig. Am. J. Cancer, vol. 39, pp. 185-198.

Loer, L. 1923 Mechanism of the sexual eycle with special reference to corpus luteum. Am. J. Anat., vol. 32, pp. 305-343.

LOEBB, L., AND W. B. Koun' 1928 The effect of injection of follieular extract on the sex organs in the guinca pig and the interaction between the follieular substances and substances given off by the corpus luteum. Am. J. Physiol., vol. 84, pp. 283-306.

Loeb, L., V. SuntzefF and E. L. Burns 1938 The effects of age and estrogen on the stroma of vagina cervix and uterus in the mouse. Science, vol. 88, pp. $432-433$.

LoNe, J. A., AND H. M. Evans 1922 The oestrons eyele in the rat and its associated phenomena. Memoirs. Univ. Cal., vol. 6, pp. 1-148.

Merckel, C., AND W. O. Nerson 1940 The relation of the estrogenie hormone to the formation and maintenance of corpora lutea in mature and immature rats. Anat. Rec., vol. 76, pp. 391-409.

Meyer, R. K., AND W. M. AlLeN 1933 The production of mucified cells in the vaginal epithelium of certain rodents by estrin and by corpus luteum extracts. Anat. Rec, vol. 56, pp. 321-343.

MiYACHi, \&. 1937 Über den Glutathiongehalt der Gewebe bei trachtigen Ratten. Jap. J. M. Se. II Biochem., vol. 3, pp. 263-265.

Moore, E., J. E. SMadel, K. F. Koknig and L. Loeb 1937 The inhibiting effect of corpus luteum on the growth stimulating action of oestrin. Growth, vol. 1, pp. 119-129.

Nelson, W. O. 1935 Gonad hormone effects in normal, spayed, and hypophysectomized rats. Anat. Rec., vol. 64, suppl. 1, p. 52 .

Nelson, W. O., and C. G. MERCKFi 1937 Effects of androgenic substances in the female rat. Proe. Soe. Exper. Biol. and Med., vol, 36, pp. 823-825. 
Newton, W. H. 1935 "Pseudoparturition" in the mouse, and the relation of the placenta to post-partum oestrus. J. Physiol., vol. 84, pp. 196-207.

Newton, W. H., AND N. BECK 1939 Placental activity in the mouse in absence of pituitary gland. J. Endocrinol., vol. 1, pp. 65-75.

Papanicolaou, G. N. 1926 A specific inhibitory hormone of the corpus luteum: its contrast with female sex (follicular) hormone. J. A. M. A., vol. 86, pp. 1422-1424.

Parkes, A. S. 1928 The role of the corpus luteum in the maintenance of pregnancy. J. Physiol., vol. 65, pp. 341-349.

Phillifs, W. A. 1937 The inhibition of estrous cycles in the albino rat by progesterone. Am. J. Physiol., vol. 119, pp. 623-626.

Phillips, W. A., AND L. E. Young 1938 Further studies on role of progesterone in inhibition of estrous cycles in albino rat. Am. J. Physiol., vol. 122, pp. 175-178.

Reimann, S. P., AND F. S. HAMMETT 1929 Cell proliferation response to sulf. hydryl in man. Proe. Soc. Exper. Biol. and Med., vol. 27, pp. 20-22

Robson, J. M. 1938 Mechanism of oestrus inhibition in the mouse during pregnancy. Quart. J. Exper. Physiol., vol. 28, pp. 195-205.

Robson, J. M., AND B. P. WIESNER 1931 The causation of mucification and cornification in the vagina of the mouse. Quart. J. Exper. Physiol., vol. 21, pp. 217-225.

Robson, J. M., AND J. AdLer 1940 Site of action of estrogens. Nature, vol. 146, p. 60 .

Rogers, P. V., AND E. Alden 1937 Epithelial growth eaused by stimulation with various smear methods as demonstrated by mitotic stasis with colchicine. Endocrinology, vol. 21, pp. 629-632.

Santavy, F. 1938 Les variations du taux de glutathion chex les animoux nouveau-res. J. de Physiol. et de path. gen., vol. 36, pp. 1089-1096.

SCHICK, R. DEAN 1943 Changes in the whole vagina of the mouse during estrus and pregnancy. J. Morph., vol. 72, pp. 305-329.

Selye, H., J. B. Collip and D. L. Thomson 1935 Endocrine interrelations during pregnancy. Endocrinology, vol. 19, pp. 151-159.

Setye, H., J. S. L. Browne ANd J. B. Colitip 1936 Effect of large doses of progesterone in the female rat. Proc. Soc. Exper. Biol. and Med., vol. $34, \mathrm{pp}, 472-474$.

SHELESAYAK, M. C. 1931 The induction of pseudopregnancy in the rat by means of electrical stimulation. Anat. Rec., vol. 49, pp. 179-183.

Suntzeff, V., E. L. Burns, M. Moskop and L. Loeb 1938 On the proliferative changes taking place in the epithelium of vagina and cervix of mice with advancing age and under the influence of experimentally administered estrogenic hormones. Am. J. Cancer., vol, 32, pp. 256-289.

WADE, N. J., AND E. A. DoISY 1935 Cornification of vaginal epithelium of ovariectomized rat produced by smearing. Proc. Soe. Exper. Biol. and Med., vol. 32, pp. 707-709.

Worthington, R. V., AND E. ALLeN 1939 Growth of genital tissues in response to estrone as studied by colchicine technic. Yale J. Biol. and Med., vol. 12 , pp. 137-153. 


\section{PLATE 1}

EXPLANATION OF FIGURES

Vaginas of mice in eross section. $\times 20$.

1 Virgin mouse 256. Progesterone, $0.6 \mathrm{mg}$., every 4 days beginning in diestrus. Sacrificed on sixtcenth day. Vagina $64.2 \mathrm{mg}$. Mucosal eircumference $\times 160$, $382 \mathrm{~cm}$., S.E. 0.73 ; perimeter $\times 160,155 \mathrm{~cm}$. S. E. 0.46 . Body weight $22 \mathrm{gm}$.

2 Virgin mouse 416 . Fresh c. luteum of $\mathrm{hog}, 68.4 \mathrm{mg}$. every $2-3$ days, subcut., beginning in diestrus. Sacrificed on sixteenth day. Vagina $56.4 \mathrm{mg}$. Mucosal circumf. $\times 160,199$ em., S.F. 19.1 ; perimeter $\times 160,166 \mathrm{~cm}$, S. F. 9.5. Body weight, $16 \mathrm{gm}$.

3 Pseudopregnant mouse 600. Antiutrin-S, 0.2 ce. on sixth, tenth and fourteenth days after sterile copulation. Sacrificed on eigliteenth day. Vagina $74.3 \mathrm{mg}$. Mucosal circumference $\times 160,351 \mathrm{~cm}$., S.E. 8.23 ; perimeter $\times 160$, 145 cm., S.E. 2.78. Body weight, $28 \mathrm{gm}$.

4 Virgin mouse 627. Fresh placenta (mouse) directly in vaginal lumen, 10 doses (68.4 mg. each) begimning in diestrus. Sacrificed on eightecnth day. Vagina $65.9 \mathrm{mg}$. Mueosal cireumference $\times 160,364 \mathrm{~cm}$. , S.E. 13.5 ; perimeter $\times 160,157$ em., S.E. 3.5. Body weight, $24 \mathrm{gm}$.

5 Virgin mouse 523. Theelin, $0.004 \mathrm{mg}$. doses, at estrus, on fourth and eighth days afterward; glutathione, $0.4 \mathrm{mg}$. on fourth, eighth, twelfth and sixteenth days after estrus. Sacrificed on eighteenth day. Vagina $48.1 \mathrm{mg}$. Mucosal circumference $\times 160,298 \mathrm{~cm}$., S.E. 3.29 ; perimeter $\times 160,176 \mathrm{~cm}$, S.E. 3.41. Body weight, $30 \mathrm{gm}$.

6 Virgin mouse 546. Testosterone propionate, $0.5 \mathrm{mg}$. every other day begimning in estrus. Sacrificed on eighteenth day. Vagina $114.0 \mathrm{mg}$. Mucosal eircumference $\times 160,270 \mathrm{~cm}$., S.E. 3.9 ; perimeter $\times 160,170 \mathrm{~cm}$. . S.E. 1.19 . Body weight, $26 \mathrm{gm}$. 


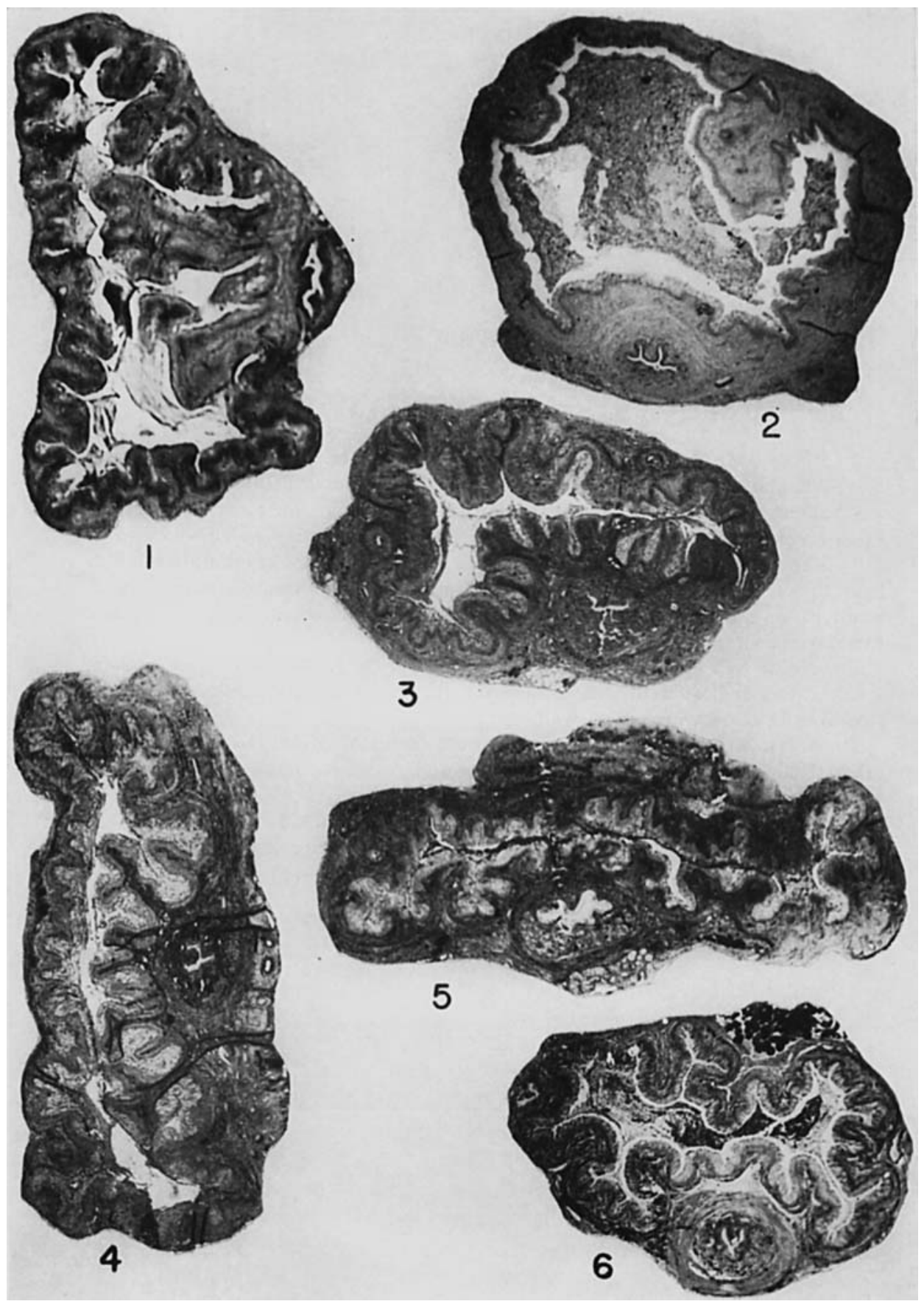




\section{PLATE 2}

\section{EXPLANATION OF FIGURES}

Sectional detail of vaginas from treated mice. $\times 200$.

7 Mouse 256. See explanation of figure 1 for data. Secretory development here is similar to that of early pregnancy. Connective tissue shows some loosening.

8 Mouse 416. See explanation of figure 2 for data. Secretory development as in early pregnancy, showing metaplasia here. Muscular layer shows loosening.

9 Mouse 600. See explanation of figure 3 for data. Few proliferative layers beneath secretory cells and absence of mitotic figures indicates interruption of proliferation at time of sacrifice. Vaginal wall shows considerable loosening and vascularization.

10 Mouse 627. See explanation of figure 4 for data. Well-developed mucosa. Proliferation indicated by mitotic activity in basal layers of epithelium. Some loosening is evident in vaginal wall,

11 Mouse 523. See explanation of figure 5 for data. Middle to late-pregnaney mucosal development shown here. Mitotic activity at time of sacrifice is evidence of further growth.

12 Mouse 546. See explanation of figure 6 for data. Mucosa of middle to late pregnancy. Proliferation retarded, but there is evidence of previous activity. 
R. DEAN SCHICK
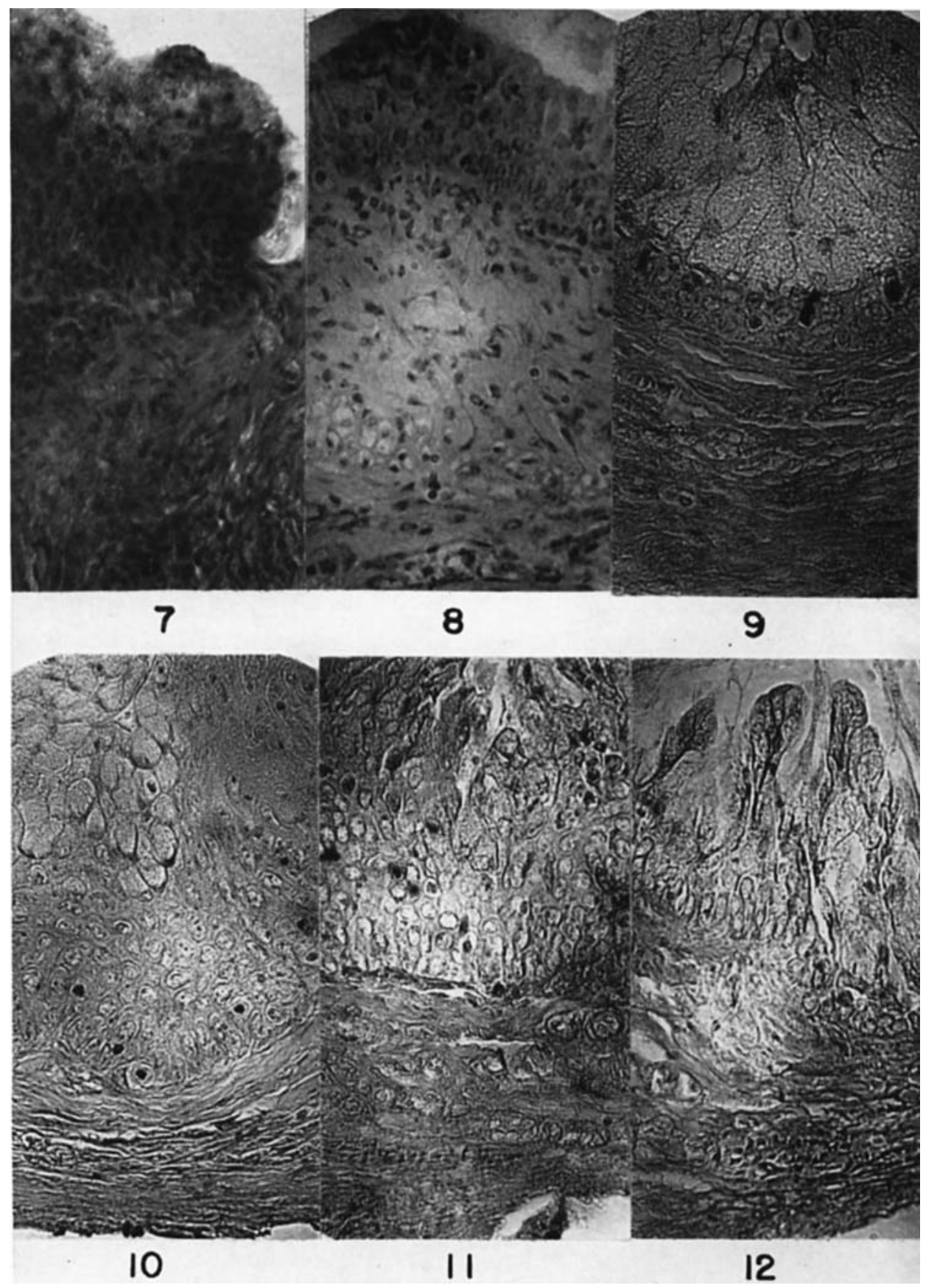